\title{
VIRTUAL AND FLYING MODELS FOR AIRCRAFT DEVELOPMENT
}

\author{
S. Chiesa, S. Corpino, M. Fioriti, N. Viola
}

Politecnico di Torino, Department of Aeronautics and Space Engineering, C. so Einaudi 40, 10129 Torino, Italy. E-mail: sergio.chiesa@polito.it,sabrina.corpino@polito.it,marco.fioriti@polito.it,nicole.viola@polito.it. Received 2701 2007, accepted 11062007
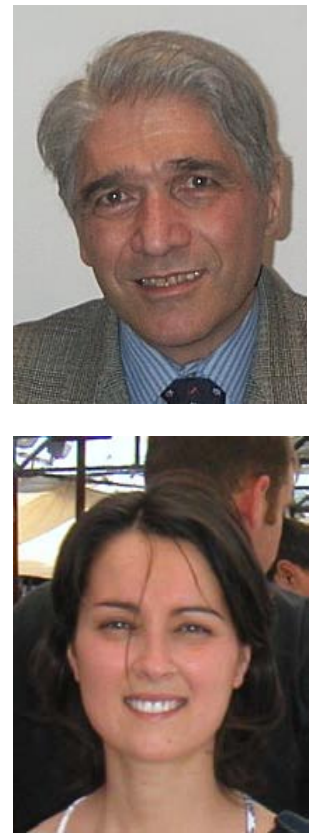

Sergio CHIESA, prof

Education: 1972 - degree of $\mathrm{PhD}$ in Aeronautical Engineering at Politecnico di Torino. For three years, he was employed in the field of quality assurance in an Italian firm involved in the Tornado program. 1976 - was enrolled at Turin Polytechnic as assistant of aeronautical design.

Affiliations and functions: since 1978 he has been teaching aeronautical systems, with particular emphasis on reliability and logistic support; since 1990 - a full professor and in the 1991 was named chairman of the Aerospace Engineering Department at Politecnico di Torino.

$\mathrm{He}$ is author of many technical papers about aircraft systems, aircraft design, and reliability and logistic support. He was a founder of the diploma course in aerospace engineering at Turin Polytechnic. Since the foundation of that program, he has been its chairman. He is the chairman of the council of "Area di Formazione" in aerospace engineering. He is editorial member of one scientific journal (Journal of Aerospace Engineering), and he operates in the "systems engineering" research group of the Aerospace Engineering Department.

Experience: a member of SOLE (District 20, Chapter 02, Northern Italy) since 1981. From 1994 to 1997 he was chairman of SOLE Chapter 02. He is a member of AIDAA and the chairman of the Turin Section.

\section{Sabrina CORPINO, assistant professor}

Date of birth: $27^{\text {th }}$ January 1973 .

Education: March 2003 - degree of PhD in Aerospace Engineering at Politecnico di Torino; October 1999 - degree of Msc in Aerospace Engineering at Politecnico di Torino.

Work experience: July 2003 - present: assistant professor of Aerospace System Engineering at Politecnico di Torino.Nov. 1999 - present: teaching at Politecnico di Torino as lecturer in CAD utilization and on-board system design and integration; teaching at Alenia S.p.A. as trainer of new employees about general aeronautical subjects; teaching at Alenia/AMMA post-lauream course as lecturer in new information technologies in aerospace design; teaching at COREP-Politecnico di Torino MSc course as lecturer in new information technologies and RAMS techniques in aerospace design; teaching at Alenia Aeronautica-Politecnico di Torino MSc in aerospace systems and modelling, simulation and testing.

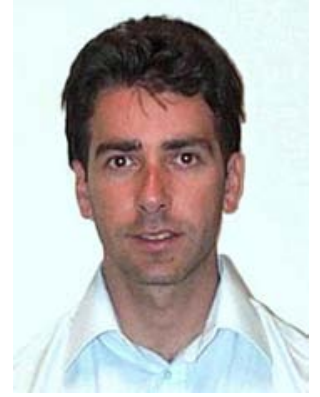

\section{Marco FIORITI, $\mathrm{PhD}$}

Date of Birth: 8 July 1980

Education and training: Jan. 2007: first year of $\mathrm{PhD}$ course in Aerospace Engineering at Politecnico di Torino. Research project: "Innovative solutions for light, ultralight and unmanned aircraft". Oct. 2006: degree of PhD in Aerospace Engineering at Politecnico di Torino.

Work experience: May-Dec. 2006: researcher in aerospace system engineering at Politecnico di Torino; Oct. 2006: tutoring and teaching design of aerospace systems at Politecnico di Torino; tutoring and teaching general aeronautical subjects to new employees at Alenia S.p.A.; July 2006: teaching at IFTS ("Istruzione Formazione Technica Superiore") in the "Technical Specialists for Production and Logistics Management" course as lecturer of Statistics and Reliability; tutoring at Alenia Aeronautica-Politecnico di Torino MSc in Aerospace Systems.

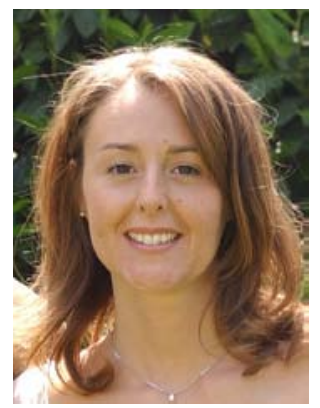

\section{Nicole VIOLA, $\mathrm{PhD}$}

Date of birth: 11 April 1973.

Education and training: Feb. 2004: PhD in Aerospace Engineering at Politecnico di Torino; Oct. 1999: Degree in Aerospace Engineering at Politecnico di Torino.

Work experience: Feb. 2004 - present: Researcher in Aerospace System Engineering at Politecnico di Torino; Apr. 2000 - present: teaching at Politecnico di Torino as lecturer in utilization of simulated tools and design and integration of aerospace systems; teaching new employees at Alenia S.p.A. about general aeronautical subjects; teaching at Alenia/AMMA post-lauream course as lecturer in new information technologies in aerospace design; Teaching at COREP-Politecnico di Torino MSc course as lecturer in aerospace design and satellite orbits; teaching at Alenia Aeronautica-Politecnico di Torino MSc in Aerospace Systems and Modelling, Simulation and Testing. 
Abstract. In the field of the widespread research activity focusing on ultra light aircraft, two different needs were merged into one single design activity: the educational necessity of getting students involved into a real design effort. Our intention was to apply the conceptual design methodologies developed by our research group, which is named ASSET (Aero Space Systems Engineering Team), to a real case study. The design case study was chosen after a thorough examination of existing vehicles. Starting from a reference aircraft, the concept of the new aircraft was then conceived and is now under completely defined. The conceptual design of the new ultra light aircraft is already finished, whereas its detailed design has just begun and is proceeding through the utilization of both virtual (3D-CAD) and physical models.

Keywords: aircraft design education, ultra light aircraft, virtual model, physical model.

\section{Introduction}

The aim of the paper is to present a design case study that has recently been dealt with by ASSET. Two different needs were merged into this design activity:

1. The educational necessity of getting students involved in a real design effort.

2. The desire to apply conceptual design methodologies developed by ASSET to a real case study. These design methodologies are characterized by the utilization of both virtual (3D-CAD) and physical models during the conceptual design phase.

The design case study, which concerns an ultra light aircraft, is thus both an educational and a research program. It is in fact the main topic of a series of coordinate theses, which can be both the final year work of the first level degree and of the second level degree of Aerospace Engineering, and, at the same time, it is the central subject of a wide research program funded by Regione Piemonte. Of course, being a design activity, it involves all different specialized disciplines, which are all integrated to accomplish the design of the system through a system engineering approach. Our research group has been involved in the educational/research activity as systems engineer for the whole program.

The light blue boxes in figure 1 represent the systems engineering activities that have already been carried out or that have yet to be carried out by our research group within the educational program of coordinate theses. Starting from the conceptual design, our activity evolves through three-dimensional parametric modelling of the ultra light aircraft and through verifications/investigations by means of scaled flying models, and it ends with the study of the installation of subsystems before further developments can take place. The yellow boxes represent the specific topics that all other Research Groups have been dealing with within the educational program of the coordinate theses. Finally, the red triangle in the figure indicates the present state of both the educational and the research program.

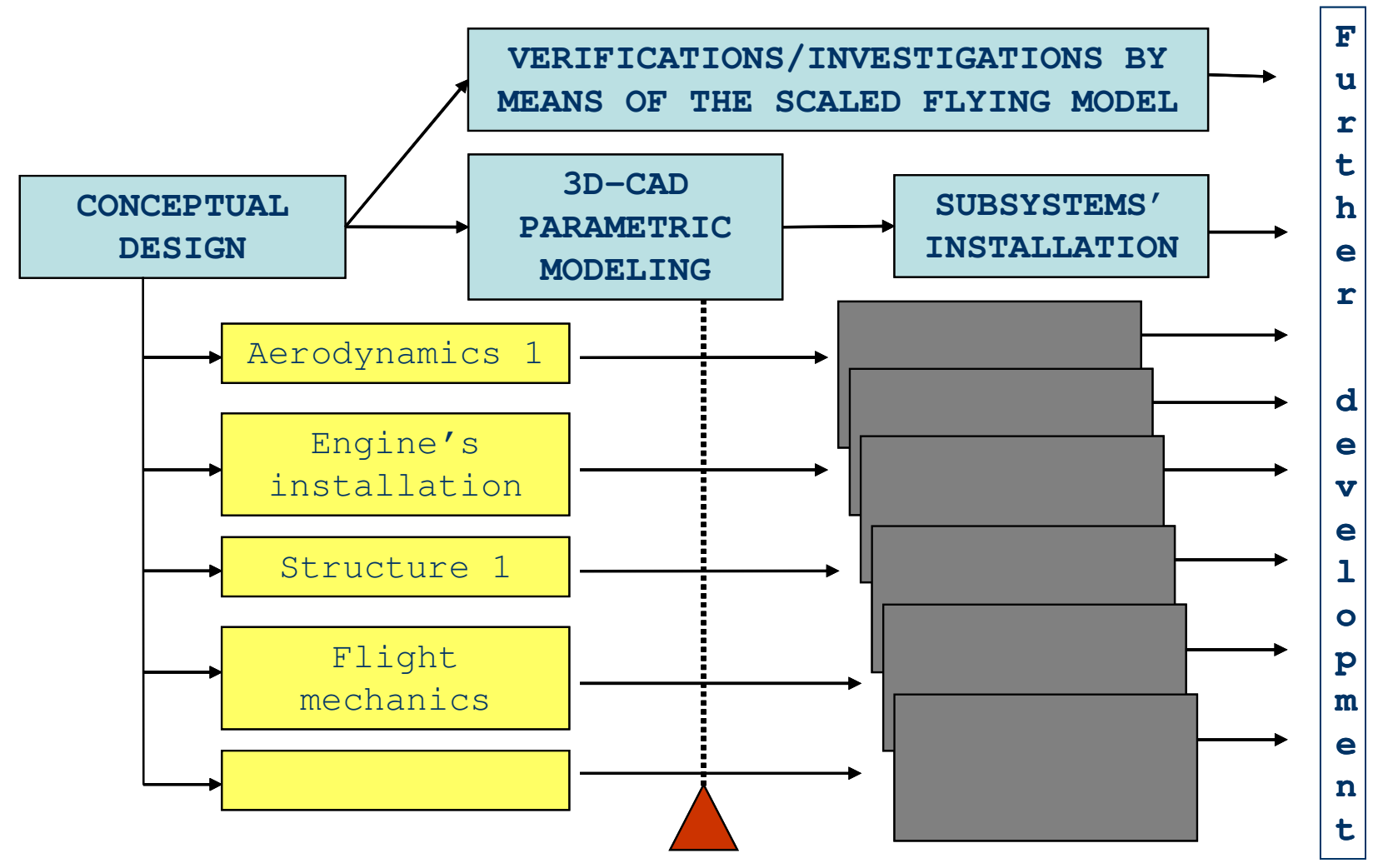

Fig 1. Topics of the research program 


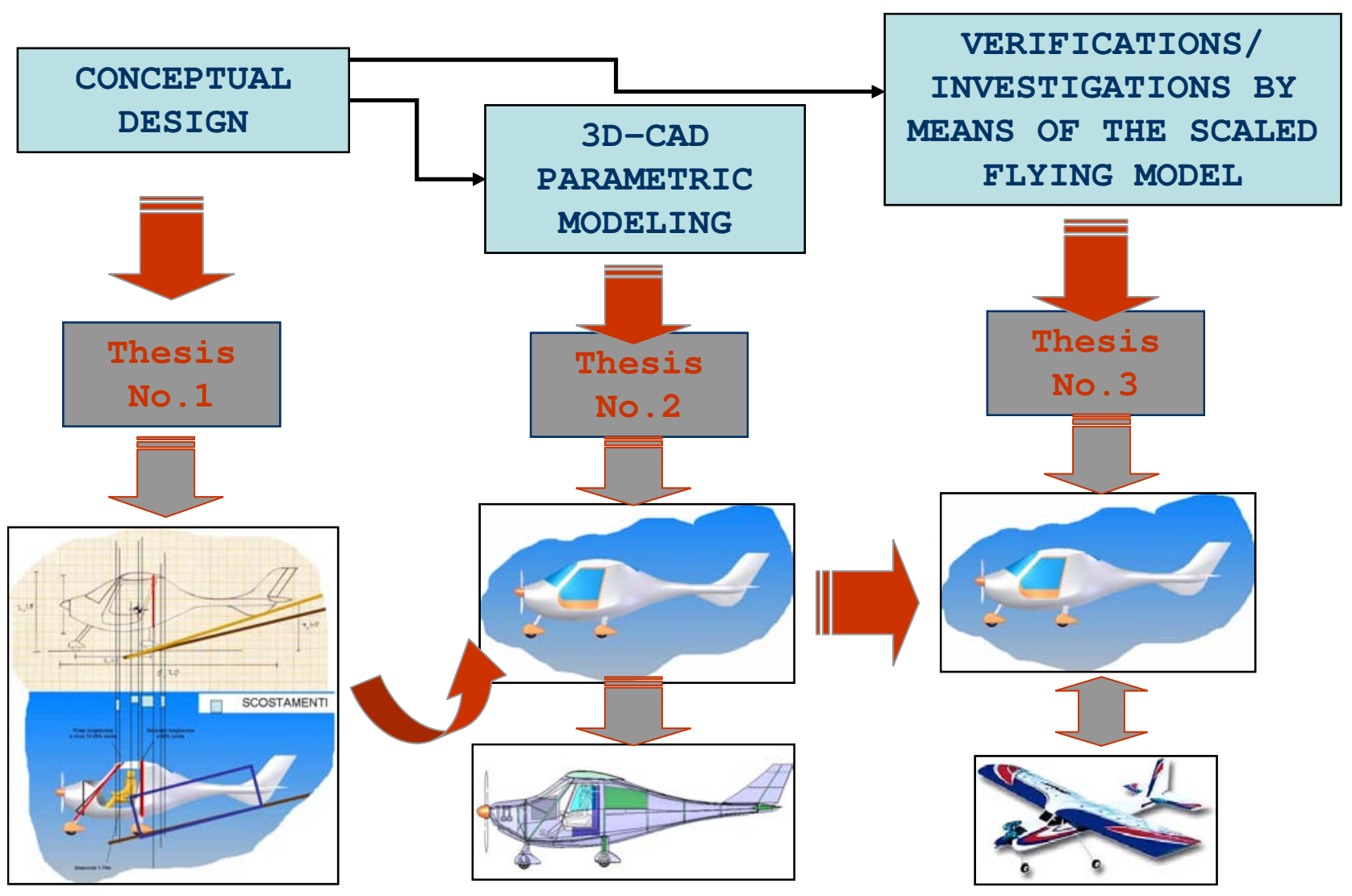

Fig 2. The system engineering approach

\section{The design case study}

As already mentioned, the design case study concerns an ultra light aircraft. There are two reasons that led to the choice of this topic:

1. A wide-spread increase in interest in the field of ultra light aircraft;

2. Research already funded by Regione Piemonte.

The growing interest in ultra light aircraft is mainly due to the fact that ultra light aircraft are currently evolving from being very simple vehicles, quite dissimilar from usual aircraft (i.e. pilot and engine inside nacelles hung up on the wing, flight controls different from those of airplanes, etc.). As a matter of fact, ultra light aircraft are becoming more complex and more similar in shape to airplanes (Tab 1).
For these reasons, we believe that pouring all knowledge and technologies acquired for airplanes over the past years into the development of new ultra light aircraft could have a tremendous impact on the progress of this type of vehicle.

Taking into account both the growing interest and the research already funded, we thought of getting many students involved into the project through their degree theses in Aerospace Engineering. The schedule of the final year work of the students is shown both in figures 12 , in which the activities that have already been accomplished are highlighted. As the study of the installation of on-board subsystems has not yet been carried out, these activities are the conceptual design, the three dimensional parametric modelling of the system, and the investigations by means of scaled flying models. Let us now better describe these activities.

Table 1. Examples of ultra light aircraft

\begin{tabular}{|c|c|}
\hline FlySynthesis Wallaby & $\begin{array}{ll}\text { - } & \text { Wing span }(\mathrm{m}): 9.42 \\
\text { - } & \text { Wing surface }\left(\mathrm{m}^{2}\right): 12.7 \\
\text { - } & \text { Aspect ratio: } 6.99 \\
\text { - } & \text { Length }(\mathrm{m}): 6.05 \\
\text { - } & \text { MTOW }(\mathrm{kg}): 425 \\
& \text { Wing loading }(\mathrm{empty} \text { weight })\left(\mathrm{kg} / \mathrm{m}^{2}\right): 15.59\end{array}$ \\
\hline $\begin{array}{l}\text { Hughes Australian } \\
\text { Light Wing GR-912 }\end{array}$ & $\begin{array}{ll}\text { - } & \text { Wing span }(\mathrm{m}): 9.42 \\
\text { - } & \text { Wing surface }\left(\mathrm{m}^{2}\right): 12.7 \\
\text { - } & \text { Aspect ratio: } 6.99 \\
\text { - } & \text { MTOW }(\mathrm{m}): 6.05 \\
& \text { Wing loading }\left(\mathrm{empty} \text { weight }\left(\mathrm{kg} / \mathrm{m}^{2}\right): 15.59\right. \\
\end{array}$ \\
\hline
\end{tabular}




\begin{tabular}{|c|c|c|}
\hline $\begin{array}{l}\text { Fantasy Air Allegro } \\
2000 \mathrm{~A}\end{array}$ & & $\begin{array}{ll}\text { - } & \text { Wing span }(\mathrm{m}): 10.81 \\
\text { - } & \text { Wing surface }\left(\mathrm{m}^{2}\right): 11.37 \\
\text { - } & \text { Aspect ratio: } 10.28 \\
\text { - } & \text { MTOW }(\mathrm{m}): 6.36 \\
\text { - } & \text { Wing loading }(\mathrm{empty} \text { weight })\left(\mathrm{kg} / \mathrm{m}^{2}\right): 25.95\end{array}$ \\
\hline Zenith STOL CH 701 & & $\begin{array}{ll}\text { - } & \text { Wing span }(\mathrm{m}): 8.23 \\
\text { - } & \text { Wing surface }\left(\mathrm{m}^{2}\right): 11.33 \\
\text { - } & \text { Aspect ratio: } 5.8 \\
& \text { Length }(\mathrm{m}): 6.38 \\
\text { - } & \text { MTOW }(\mathrm{kg}): 499 \\
& \text { Wing loading (empty weight }\left(\mathrm{kg} / \mathrm{m}^{2}\right): 19.24\end{array}$ \\
\hline FlySynthesis Storch CL & & $\begin{array}{ll}\text { - } & \text { Wing span }(\mathrm{m}): 10.14 \\
\text { - } & \text { Wing surface }\left(\mathrm{m}^{2}\right): 13.02 \\
\text { - } & \text { Aspect ratio: } 7.89 \\
& \text { Length }(\mathrm{m}): 6.25 \\
\text { - } & \text { MTOW }(\mathrm{kg}): 450 \\
& \text { Wing loading (empty weight }\left(\mathrm{kg} / \mathrm{m}^{2}\right): 19.2 \\
\end{array}$ \\
\hline Jannotta San Francesco & & $\begin{array}{ll}\text { - } & \text { Wing span }(\mathrm{m}): 9.74 \\
\text { - } & \text { Wing surface }\left(\mathrm{m}^{2}\right): 14.61 \\
\text { - } & \text { Aspect ratio: } 7.3 \\
\text { - } & \text { Length }(\mathrm{m}): 6.49 \\
\text { - } & \text { Wing loading }\left(\mathrm{empty} \text { weight }\left(\mathrm{kg} / \mathrm{m}^{2}\right): 19.16\right. \\
\end{array}$ \\
\hline Jabiru Calypso & & $\begin{array}{ll}\text { - } & \text { Wing span }(\mathrm{m}): 9.56 \\
\text { - } & \text { Wing surface }\left(\mathrm{m}^{2}\right): 9.29 \\
\text { - } & \text { Aspect ratio: } 9.84 \\
\text { - } & \text { Length }(\mathrm{m}): 5.64 \\
\text { - } & \text { MTOW }(\mathrm{kg}): 450 \\
\end{array}$ \\
\hline $\begin{array}{l}\text { Tecnam P92 Echo } \\
\text { Super }\end{array}$ & & $\begin{array}{ll}\text { - } & \text { Wing span }(\mathrm{m}): 8.7 \\
\text { - } & \text { Wing surface }\left(\mathrm{m}^{2}\right): 12 \\
\text { - } & \text { Aspect ratio: } 6.3 \\
& \text { Length }(\mathrm{m}): 6.4 \\
\text { - } & \text { MTOW }(\mathrm{kg}): 450 \\
& \text { Wing loading (empty weight }\left(\mathrm{kg} / \mathrm{m}^{2}\right): 23.42 \\
\end{array}$ \\
\hline Flight Design CT 912 & 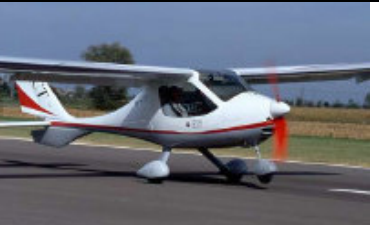 & $\begin{array}{ll}\text { - } & \text { Wing span }(\mathrm{m}): 9.3 \\
\text { - } & \text { Wing surface }\left(\mathrm{m}^{2}\right): 10.8 \\
\text { - } & \text { Aspect ratio: } 8.01 \\
& \text { Length }(\mathrm{m}): 6.22 \\
\text { - } & \text { MTOW }(\mathrm{kg}): 600 \\
& \text { Wing loading (empty weight }\left(\mathrm{kg} / \mathrm{m}^{2}\right): 25.46\end{array}$ \\
\hline
\end{tabular}

\section{Conceptual design}

As far as conceptual design is concerned, the Flight Design CT has been the real source of inspiration for our work, even though our aim has been the reduction of MTOW below $450 \mathrm{~kg}$ (according to Italian regulations for this type of aircraft). In table 2, the main data for the ultra light aircraft we desire to develop are listed. These data are the results of the conceptual design phase, which has been carried out by means of a statistical approach based on existing ultra light aircraft. Another result of the design phase is, of course, the three-view drawings of the aircraft, illustrated in table 2 .

Table 2. Results of the conceptual design phase

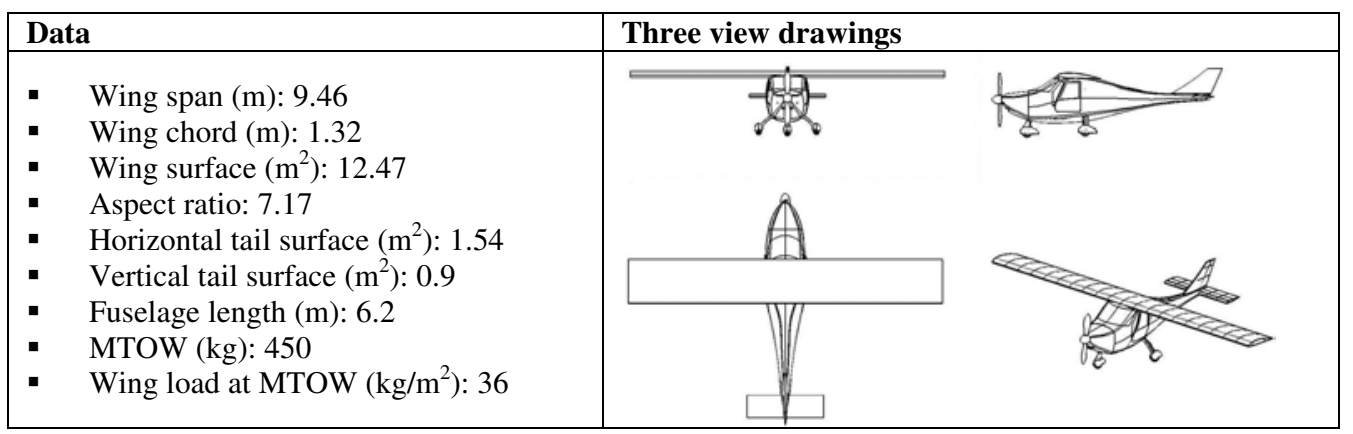




\section{Verifications/investigations by means of a scaled flying model}

Once the conceptual design phase is completed, keeping in mind our target, which is the development of an ultra light aircraft, the design process has to evolve until the detailed design activity is completed. In order to do so, cost-effective and low risk research methods, which employ small-scaled vehicles, can be used and we have actually used them. This approach is a popular one as many research programs testify. Some of these programs dealing with ultra light aircraft are shown in tables 3-4.

Table 3. Scaled flying model of ISKRA II airplane

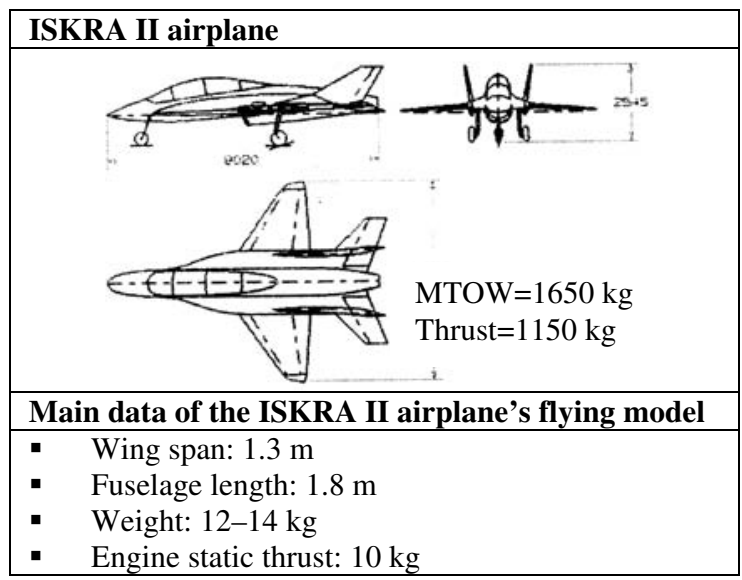

In particular, table 3 illustrates the results of a research activity which focuses on a 1/5-scaled model of the ISKRA II airplane (the project was carried out at Warsaw University of Technology a few years ago [5]), whereas table 4 presents two other interesting research programs: one has been carried out recently by Mag S.a.s. in Rome, Italy in order to develop the Mag 1 ultra light aircraft, and the other is the scaled flying model of a future ultra light aircraft named Mantos and designed by FlySynthesis in Udine, Italy (Tab 4, Fig 3) [2, 1].

Table 4. Mag 1 ultra light aircraft

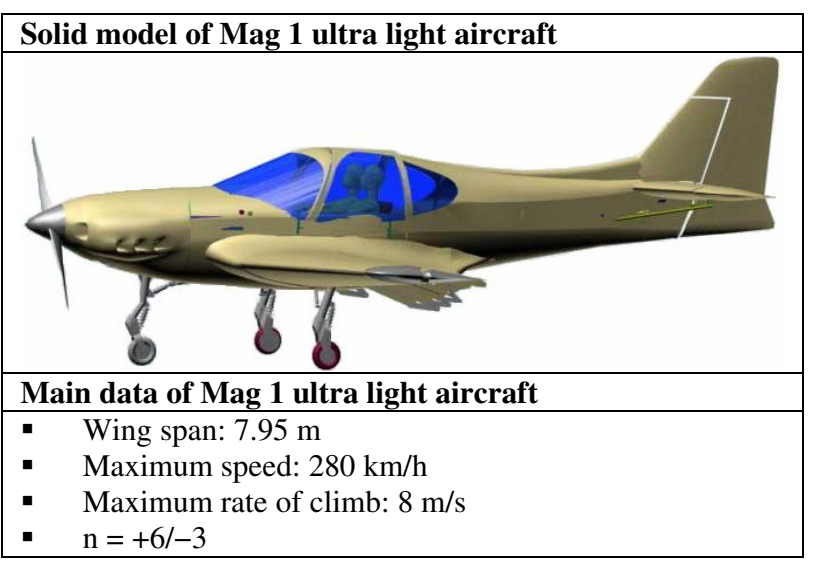

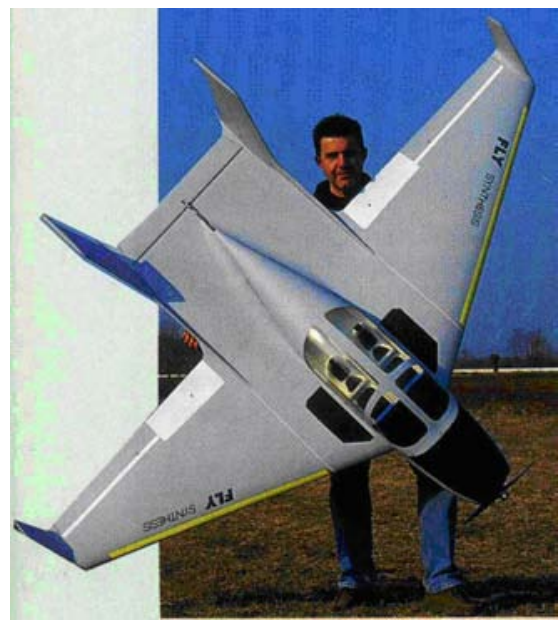

Fig 3. Scaled flying model of Mantos

As far as the former is concerned, Mag S.a.s. has made thorough investigations by means of two different scaled flying models:

1) the first one is a commercial flying model, which has been useful setting up the test instrumentation of the proper ultra light aircraft's scale model (Fig 4);

2) the second flying model is the previously mentioned proper ultra light aircraft's scale model. As can be noted, in fact, unlike the commercial model, the external shape of this scaled flying model is exactly the same as that of the Mag 1, the ultra light aircraft. This means that there is perfect geometrical similarity between the Mag 1 and the scale model (Fig 5).

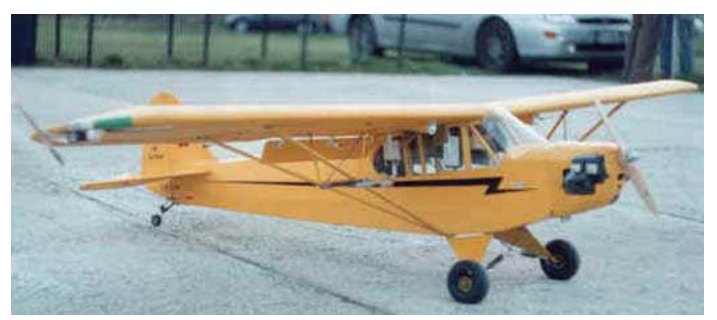

Fig 4. Commercial flying model of Mag 1

The research approach used to develop the Mag 1 seems to be quite interesting because the commercial flying model can be really cost-effective as it is a lowcost system that is very useful for arranging the test instrumentation that will later on be installed on board the scaled flying model. For this reason, we thought that the same approach could also be good for our work.

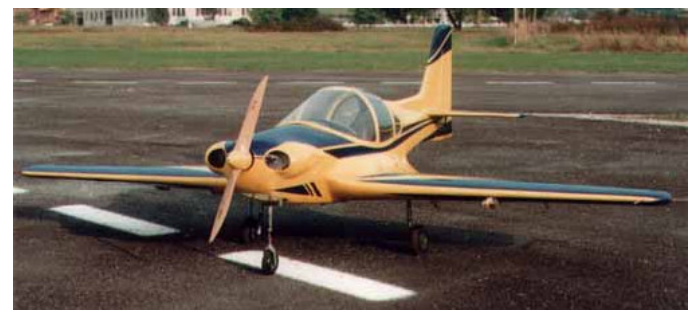

Fig 5. Scaled flying model of Mag 1 
Figure 6 illustrates how all-various activities of our project are expected to evolve through time (which is on the $\mathrm{x}$-axis) and what the relations between them are. Starting from the conceptual design phase and moving on to the detailed design phase, two activities that are crucial for the completion of the detailed design be shown in figure 6. They are:

1. The design of tests that have to be performed by means of the scaled flying model and the design of the model itself. Definition and set-up of the test instrumentation, thanks to a commercial radio-controlled flying model.

2. The manufacture of the scaled flying model of the ultra light aircraft.

Quite obviously, only after the scale model of the ultra light aircraft has been built, can the test campaign start. But the manufacture of this model cannot begin until the external shape of the ultra light aircraft itself has been frozen. The state of our research activities is indicated by the green triangle at the bottom of Figure 6 . We have just started some tests with the commercial flying model, which, however, has not yet been equipped with all the instruments it needs.

The definition and set-up of the test instrumentation, by means of a commercial radio-controlled model, has been the focus of one final year project. The student started from an analysis of the well-known theory of similarity, which is briefly referred to in figure 7 [3]. As can be noted, once you choose the value of the scale factor $\lambda_{\mathrm{L}}$ (defined as the ratio between the real airplane length and the length of the scale model) and remembering that the ratio between both the linear acceleration and the density of the real and scale model have to equal 1, the ratio of all other corresponding characteristics between real airplane and scale model are established, as table 5 shows.

The theory of similarity must then be applied to our case study, in which the ultra light aircraft is the one we want to develop and the scaled model is the commercial radio-controlled model Hype Trainer 70 Maxi, shown in figure 8 . There are three main reasons that justify the choice of this model:

1. It is easy to pilot.

2. It is flexible for the installation of equipment.

3. It has a good compliance with scale factors $\left(\lambda_{\mathrm{L}}=5\right)$, as shown in table 6 , apart from the horizontal tail surface, because of the very high longitudinal stability, usually considered for aerial models.

Table 5. Theory of similarity

\begin{tabular}{|l|l|}
\hline Length & $\lambda_{\mathrm{L}}$ \\
\hline Surface & $\lambda_{\mathrm{L}}^{2}$ \\
\hline Volume & $\lambda_{\mathrm{L}}^{3}$ \\
\hline Linear velocity & $\lambda^{0.5}{ }_{\mathrm{L}}$ \\
\hline Angular velocity & $\lambda^{-0.5} \mathrm{~L}$ \\
\hline Time & $\lambda^{0.5} \mathrm{~L}$ \\
\hline Linear acceleration & 1 \\
\hline Angular acceleration & $\lambda_{\mathrm{L}}^{-1}$ \\
\hline Mass & $\lambda_{\mathrm{L}}^{3}$ \\
\hline Force & $\lambda_{\mathrm{L}}^{3}$ \\
\hline Work & $\Lambda_{\mathrm{L}}^{4}$ \\
\hline Power & $\lambda^{3.5}$ \\
\hline
\end{tabular}

As you can see from figure 8, the external configuration of the commercial flying model is quite different from that of the ultra light aircraft (Tab 2). In particular, we can say that the shape of the commercial model is worse from an aerodynamic point of view than that of the aircraft. This fact obviously implies worse aerodynamic performance, in particular a worse aerodynamic parasite drag coefficient. Another difference between the model and the real plane is the propulsion system: in fact, as you can note from table 7 , while the ultra light engine is a 4-stroke engine, the commercial flying model uses an electric motor.

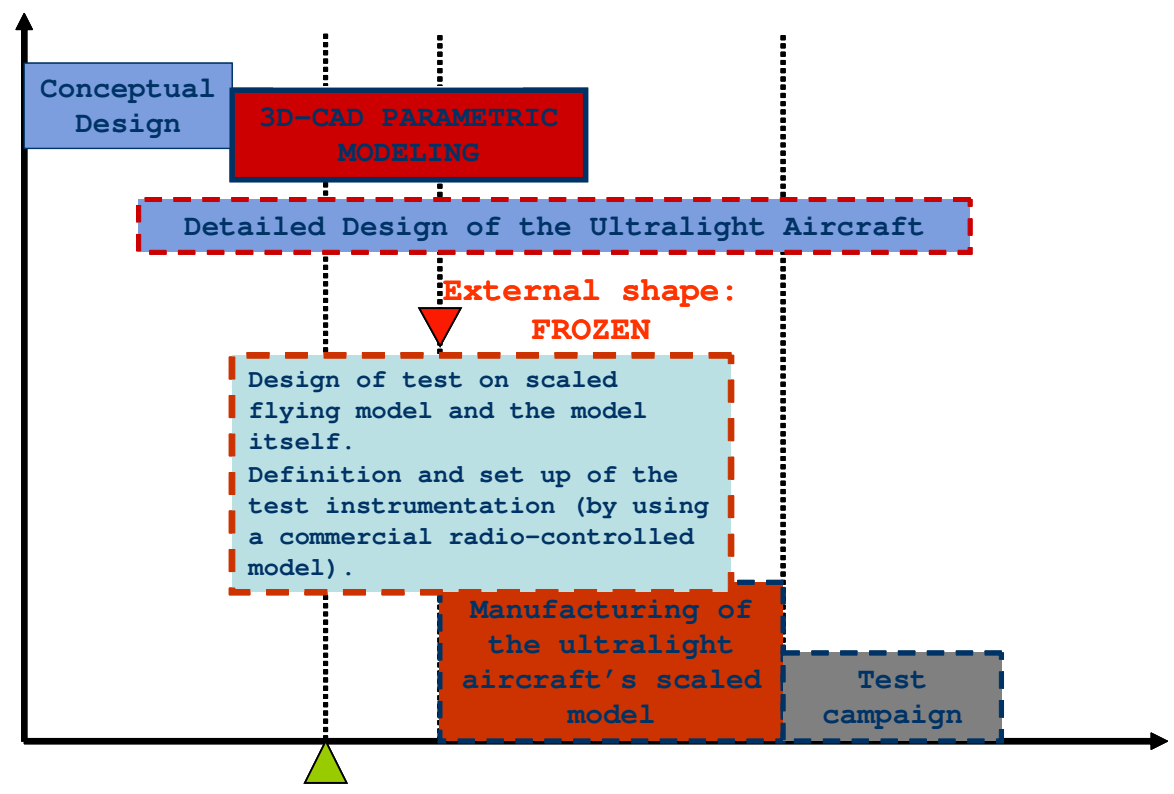

Fig 6. Evolution of the design activities with time 

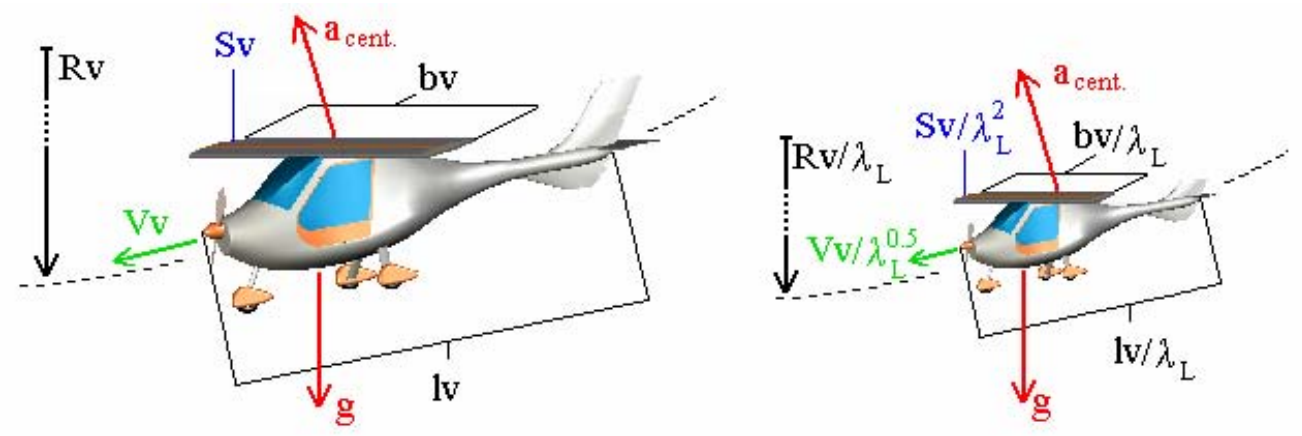

Fig 7. Theory of similarity

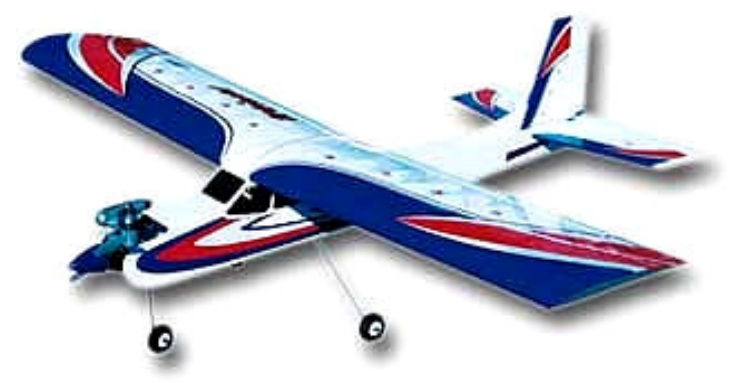

Fig 8. Commercial flying model Hype Trainer 70 Maxi

More data about the commercial flying model are listed in table 7 , where you can see the scale factor between the ultra light aircraft and the scale model, the values of the characteristics of the ultra light aircraft obtained from the conceptual design phase, the real values of the characteristics of the commercial model, the expected values of the characteristics of a scaled model, which is perfectly similar, from the geometrical point of view, to the ultra light aircraft, and the difference between these two last values, expressed as a percentage.

As has already been said, the commercial flying model is useful for setting up the avionics of the future scale model of the ultra light aircraft. Quite obviously, defining and testing the avionics is a fundamental activity, and therefore it has to be dealt with carefully.
Our hypothesis of avionics for the commercial flying model is shown in the block diagram of figure 9 . We think that both the autopilot (AP50) and the inertial measurement unit (IMU), which constantly communicate with the embedded PC (PC 104), can be installed on board the flying model. This PC is in turn linked to a radio modem to transmit telemetry data to a similar radio modem on the ground, where it is connected to a PC to manage and visualize telemetry data.

Our idea is that at the beginning the commercial model could be either radio-controlled by means of the usual radio control transmitter and receiver, as the yellow box in figure 9 shows, or autonomously controlled, at least during certain phases of the flight, by the autopilot installed on-board. In a second stage of the program, the radio control system could be definitely abandoned, and the flying model could then receive new commands either directly from the PC on the ground or, at least during certain phases of the flight, directly from the embedded PC. We have mentioned the autopilot and the IMU connected to the embedded PC, but there is one more sensor connected to the same PC on board that we have not mentioned yet: the propeller thrust measuring device, which, thanks to a dynamometer and sliding tracks, useful for installing the electric motor, should measure the propeller thrust. This device is currently being studied.

Table 6. More data about the commercial flying model

\begin{tabular}{|c|c|c|c|c|c|}
\hline Characteristic & $\begin{array}{c}\text { Scale factor } \\
(\lambda=5)\end{array}$ & $\begin{array}{l}\text { Ultra light } \\
\text { values }\end{array}$ & $\begin{array}{c}\text { Real values of } \\
\text { commercial model }\end{array}$ & $\begin{array}{c}\text { Required values of similar } \\
\text { flying model }\end{array}$ & $\begin{array}{c}\text { Difference } \\
\%\end{array}$ \\
\hline Wing span (m) & 5 & 9.46 & 1.9 & 1.89 & $+0.5 \%$ \\
\hline Chord (m) & 5 & 1.32 & 0.279 & 0.264 & $+5.7 \%$ \\
\hline Wing surface $\left(\mathbf{m}^{2}\right)$ & 25 & 12.47 & 0.53 & 0.5 & $+6 \%$ \\
\hline Aspect ratio & 1 & 7.17 & 6.81 & 7.17 & $-5 \%$ \\
\hline $\begin{array}{l}\text { Horizontal tail } \\
\text { surface }\left(\mathbf{m}^{2}\right)\end{array}$ & 25 & 1.51 & 0.147 & 0.0604 & $+143 \%$ \\
\hline $\begin{array}{l}\text { Vertical tail surface } \\
\left(\mathbf{m}^{2}\right)\end{array}$ & 25 & 0.9 & 0.04 & 0.036 & $+11.1 \%$ \\
\hline Fuselage length (m) & 5 & 6.2 & 1.2 & 1.24 & $-3.2 \%$ \\
\hline MTOW $(\mathbf{k g})$ & 125 & 450 & 4 & 3.6 & $+11.1 \%$ \\
\hline $\begin{array}{l}\text { Wing loading at } \\
\text { MTOW }\left(\mathbf{k g} / \mathbf{~ m}^{2}\right)\end{array}$ & $125 / 25=5$ & 36 & 7.55 & 7.2 & $+4.8 \%$ \\
\hline
\end{tabular}


Table 7. Ultra light aircraft and commercial flying model engines

\begin{tabular}{|c|c|}
\hline \multicolumn{2}{|c|}{ Rotax 912: airplane engine } \\
\hline $\begin{array}{ll}\text { - } & \text { Four-stroke } \\
\text { - } & \text { Four opposed cylinders } \\
\text { - } & \text { Liquid/air-cooled } \\
\text { - } & \text { Pompression ratio: 9:1 } \\
\text { - } \quad \text { Consumption: } 24 \text { 1/h at Pmax } \\
\text { - } \quad \text { Displacement: } 1.21 .\end{array}$ & \\
\hline \multicolumn{2}{|c|}{ AXI 4120/18 Gold Line : commercial flying model engine } \\
\hline $\begin{array}{l}\text { - } \quad \text { Brushless motor } \\
\text { Maximum efficiency, } \eta \max =0.86 \\
\text { - } \quad \text { MPM per Volt: } 510 \mathrm{RPM} / \mathrm{V} \\
\quad \text { Maximum power output, } \operatorname{Pmax} \approx 550 \mathrm{~W}\end{array}$ & \\
\hline
\end{tabular}

\section{D-CAD parametric modelling}

So far we have talked about scaled flying models, but there is another model that is worth remembering: the three-dimensional parametric model of the aircraft that allows us to physically simulate the vehicle we intend to develop and that is very useful throughout the design process (Fig 6).

As shown in figure 6, the activity of threedimensional modelling begins before the external shape of the ultra light aircraft is frozen. Therefore the possibility of changing the model without major effort while the design evolves is highly desirable. This is possible if the 3D-CAD model is parametric, which means, for example, that if we change the size of the fuselage then the structure varies as well automatically. The definition of the independent parameters that control the CAD model is the most delicate operation to be made within the processes of creating the solid model of aircraft and the setting up of the relations between these parameters and other dimensions of the model.

The 3D-CAD parametric model is quite complex, as both table 8 and figure 7 show. In particular, table 8 presents some details of the model, whereas figure 7 illustrates the complete three-dimensional model of the ultra light aircraft. The 3D-CAD parametric model is quite complex, as both table 8 and figure 10 show. In the upper right-hand side image in table 8 , the control structure of the fuselage is shown and illustrates how the fuselage has been obtained, i.e. by means of lofting eight control sections with guide curves. The bottom left-hand side image in the same table depicts the coarse solid model of the aircraft before any detail has been added, whereas the other pictures show some details of the model. Figure 10 illustrates the complete threedimensional parametric solid model of the ultra light aircraft.

As mentioned above, the three-dimensional model of the ultra light aircraft will continue changing until the external shape of the vehicle is frozen. Then the solid model will be useful for both the aerodynamic and the structural specialists to perform, respectively, CDF and the FEM analyses, and it will be useful for us, systems engineers, to accomplish the installation of all its subsystems (i.e. digital mock-up) on board the aircraft.
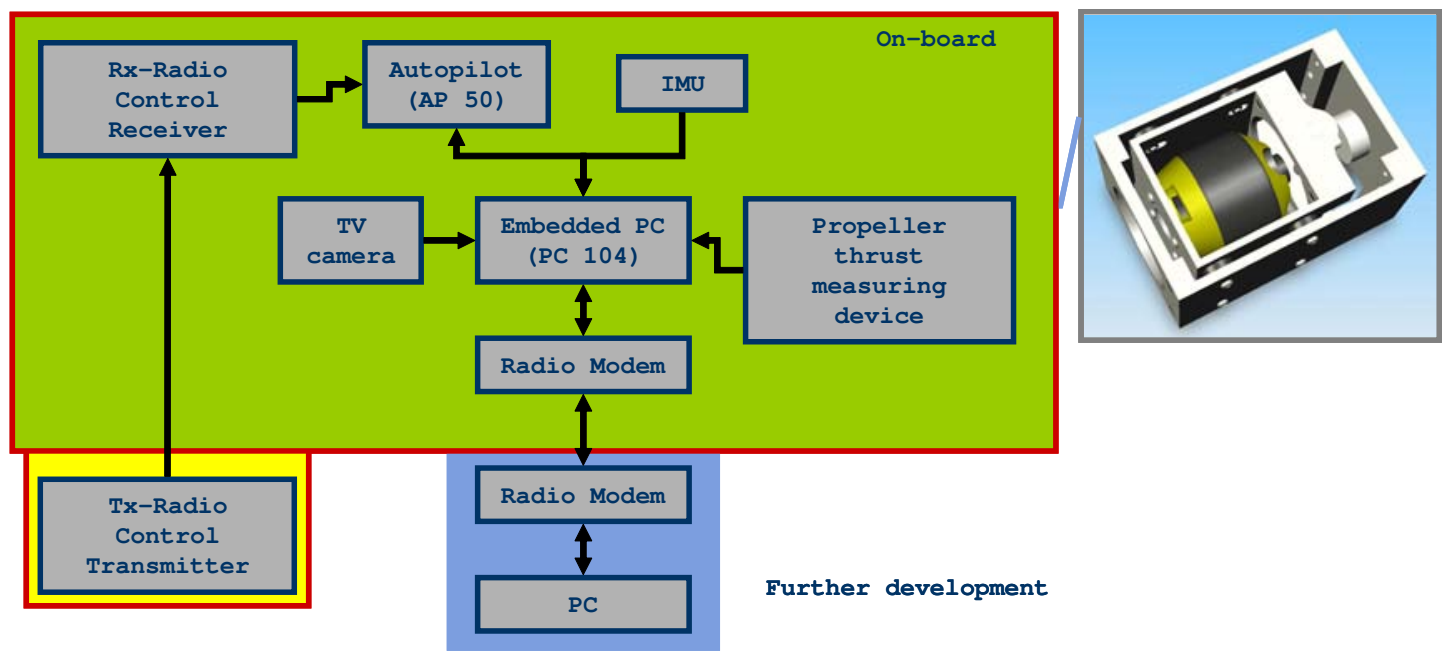

Fig 9. Avionics of the commercial flying model 


\section{Conclusion}

As shown in Figure 6 by the green triangle, which indicates the state of the project, the research program is far from being completed. The external shape of the ultra light aircraft has not yet been frozen and some important decisions still need to be taken. In particular, one crucial choice that has not been made yet concerns the most appropriate value for the scale factor between the real airplane and the flying model $\left(\lambda_{\mathrm{L}}\right.$ could either be equal to
2.5 or to 5). However, some interesting results have already been obtained:

- The conceptual design phase has been completed.

- The three-dimensional parametric modelling has started.

- Investigation by means of a commercial flying model has begun. Talking about this model, in particular, it is worth mentioning that it has already performed a few successful flights (Fig 11).

Table 8. 3D-CAD parametric modelling
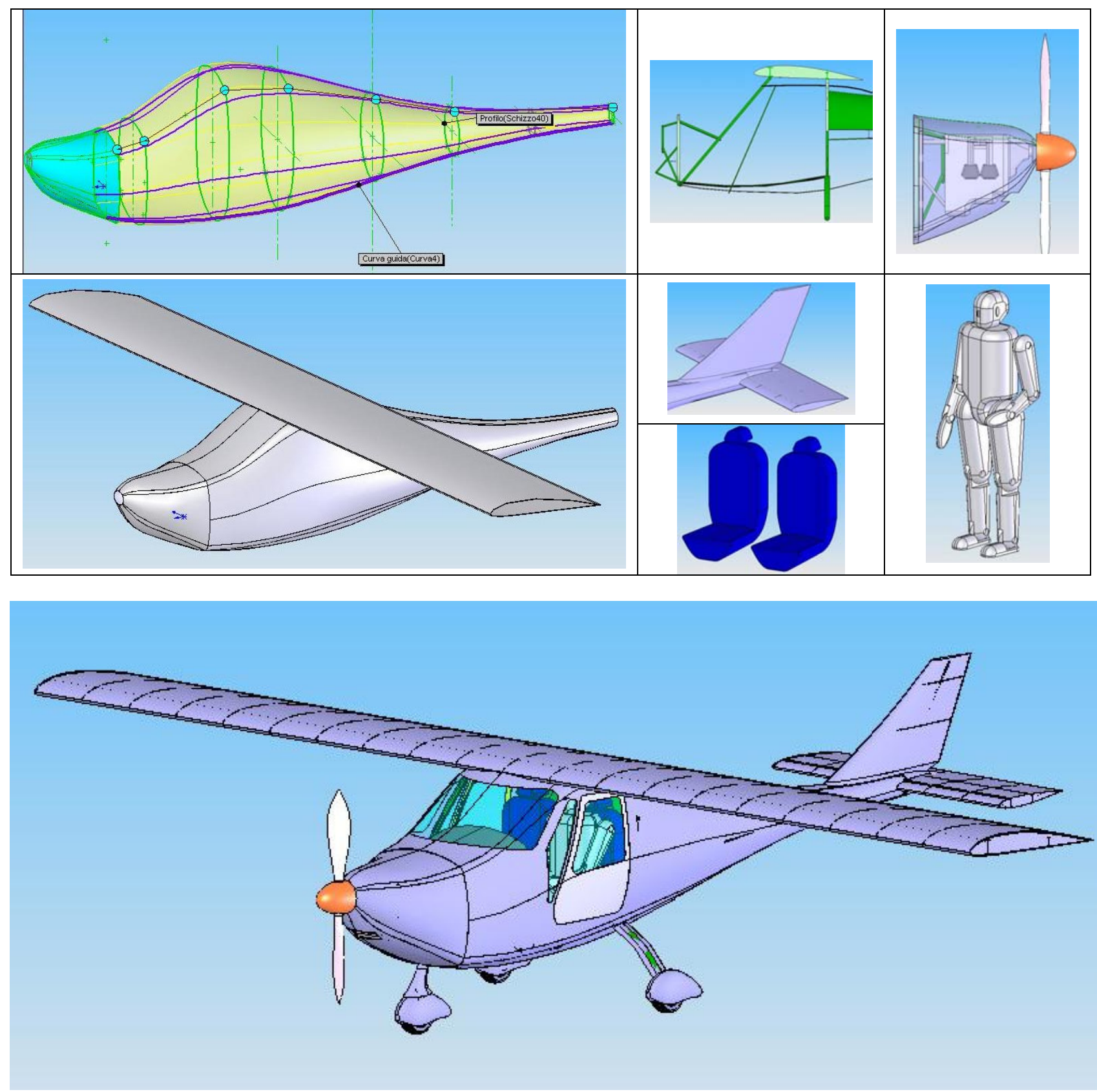

Fig 10. 3D-CAD parametric model of the ultra light aircraft 


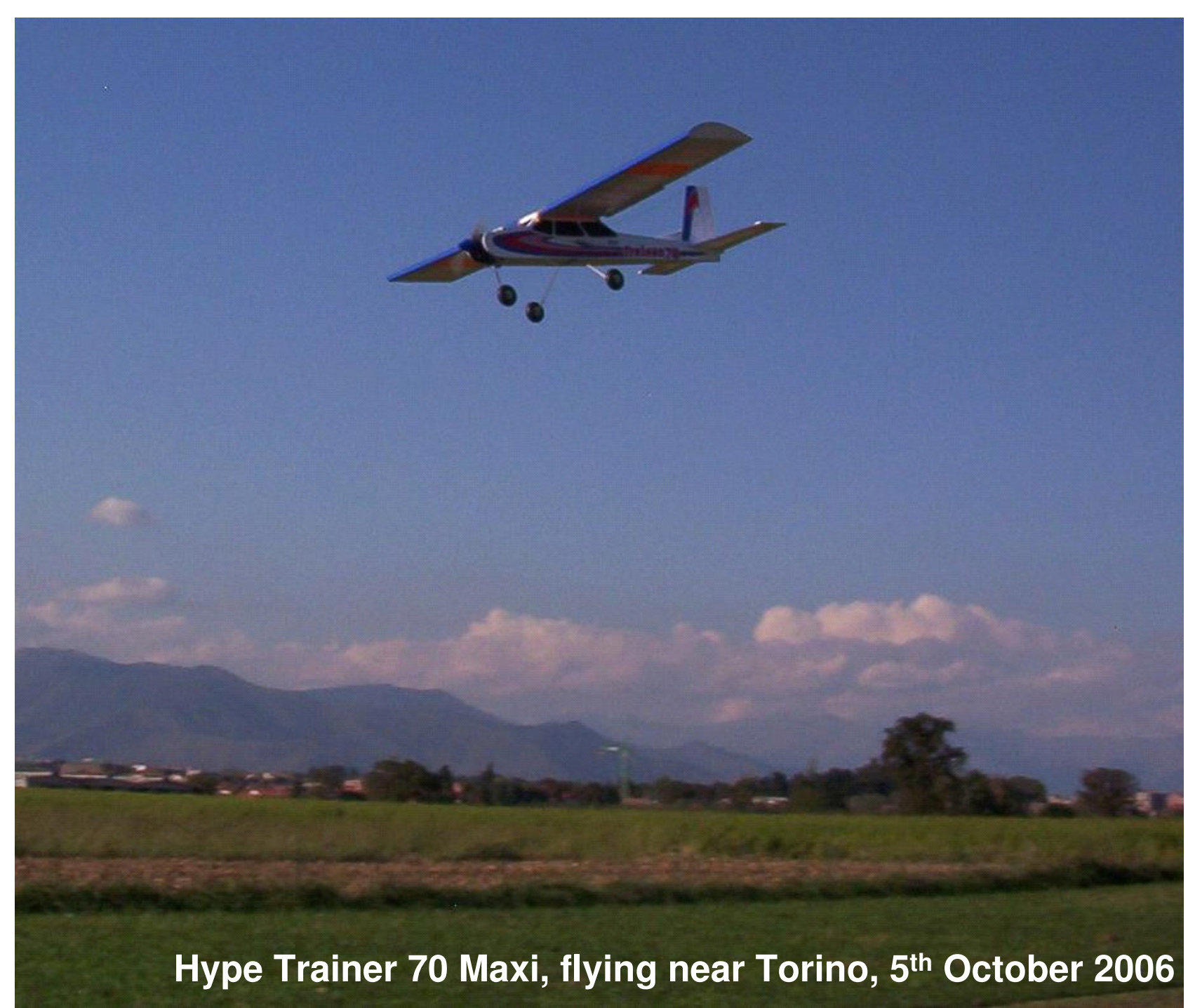

Fig 11. Hype trainer 70 maxi flying near Torino, Italy

\section{References}

1. http://www.flysynthesis.com/eng_version/new manthos.html

2. http://www.mag1.it

3. CHIESA, S. Similitudine fisica. Cooperativa Libraria Universitaria Torinese - Editrice, Sept. 1981.

4. CHIESA, S., CORPINO, S., VIOLA, N. et al. Mini-UAV remote control: A case study at Politecnico di Torino. Aviation. Vilnius: Technika, 2004, vol. 8, no. 3, p. 31-40.

5. SZENDER, M. ISKRA II - a scaled remotely piloted vehicle research program. In Proceedings of the Fourth International Seminar on RRDPAE 2000. Warsaw, Poland, Dec. 2000. 